\title{
Experimental Study On Expanding Composite Wall
}

\author{
Yonggang Zhang ${ }^{1, \text { a }}$, Yangang Zhao ${ }^{2, b}$ \\ ${ }^{1}$ Beijing Jiaotong University, Beijing 100044, China \\ ${ }^{2}$ Beijing Foreign Studies University, Beijing 100089, China \\ a16391475@qq.com, b80700023@qq.com
}

Keywords: multi-ribbed composite wall; expanding composite wall; seismic performances; failure mechanism.

\begin{abstract}
Based on the traditional ecological composite wall, expanding composite wall is put forward in this paper. Based on the tests of five pieces of 1/2 scaled expanding composite wall under low-cycle lateral loading, the bearing capacity, ductility, hysteretic characteristics, and stiffness degradation performance of the walls are analyzed. The results show that, all the five pieces of wall are subjected to shearing failure which are ideal failure modes, they all come through elastic, elastic-plastic and failure stage. Because of different constrained types, the damage processes of different walls are different during the test process. Frame, ribs and concrete blocks are under reciprocal bond, which results in improving the bearing capacity of the wall, keeping the wall from cracking, and giving full play to their energy-dissipating capacity. L-type light steel keel rib and C-type steel frame can significantly increase the constraint on blocks, effectively limit the development of wall cracks, and greatly improve the seismic performance of the walls. EPS lightweight aggregate wall block can improve the ductility of the wall without reducing the ultimate bearing capacity.
\end{abstract}

\section{Introduction}

The assembly structure can save labor cost and become the main development direction in the field of architectural structure, and the related research on the prefabricated wall is becoming the research hotspot.

At present, main prefabricated wall structure system in China is that: Chen Jinshi ${ }^{[1]}$ put forward the whole precast monolithic shear wall structure (NPC) system, zhang $\mathrm{wei}^{\left[{ }^{[2]}\right.}$ put forward the prefabricated round orifice plate shear wall structure system, Yao Qianfeng ${ }^{[3]}$ put forward the multi-ribbed composite wall system, Huang $\mathrm{Wei}^{[4]}$ put forward the ecological composite wall structure system.

Based on the on-site installation of typical prefabricated wall, the wall composed by blocks, ribs, and frame. According to the different block type, rib form, and frame shape, five common composite walls had been produced. Through vertical loading test and push over test, bearing capacity, ductility, hysteretic characteristics, $\mathrm{t}$ stiffness degradation rule, and other key parameters were got. The basic characteristics of the wall was mastered and which lay a foundation for practical application in the future.

\section{Experiment overview}

\section{Wall design}

There were 5 pieces of $1 / 2$ scaled walls model which named EC-1 EC-5 in this test. The walls structure diagram shown as figure 1, the wall design form, size and reinforcement are shown in table 1 and table 2. The size of all the five specimens size is $1400 \mathrm{~mm}^{*} 1440 \mathrm{~mm} * 100 \mathrm{~mm}$ (width $\mathrm{x}$ height $\mathrm{x}$ thick). 


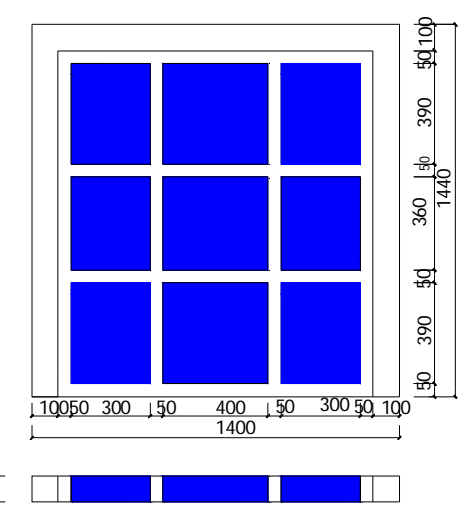

Fig.1 Sketch map for walls ( unit : mm )

Tab.1 Design form of walls

\begin{tabular}{|c|c|c|c|}
\hline $\begin{array}{c}\text { numb } \\
\text { er }\end{array}$ & frame & rib & block \\
\hline EC-1 & rebar & rebar & filling block \\
\hline EC-2 & $\begin{array}{c}\text { shape st } \\
\text { eel }\end{array}$ & rebar & filling block \\
\hline EC-3 & rebar & $\begin{array}{c}\text { lightgage stee } \\
\text { l joist }\end{array}$ & filling block \\
\hline EC-4 & rebar & rebar & LEP-J block \\
\hline EC-5 & rebar & rebar & EPS block \\
\hline
\end{tabular}

Tab. 2 Size and reinforcement for walls

numb frame beframe colu frame stir rib bea rib colu rib stirr

\begin{tabular}{|c|c|c|c|c|c|c|}
\hline er & am & $\mathrm{mn}$ & rup & $\mathrm{m}$ & $\mathrm{mn}$ & up \\
\hline EC-1 & $4 \varphi 6$ & $4 \varphi 6$ & $\varphi 2 @ 100$ & $4 \varphi 4$ & $4 \varphi 4$ & $\begin{array}{c}\varphi 2 @ 10 \\
0\end{array}$ \\
\hline EC-2 & $4 \varphi 6$ & $4 \varphi 6+C 5$ & $\varphi 2 @ 100$ & $4 \varphi 4$ & $4 \varphi 4$ & $\begin{array}{c}\varphi 2 @ 10 \\
0\end{array}$ \\
\hline EC-3 & $4 \varphi 6$ & $4 \varphi 6$ & p2@100 & $\begin{array}{l}\text { L30 } 3030 \mathrm{~L} \\
\times 3\end{array}$ & $\begin{array}{c}30 \times 30 \\
\times 3\end{array}$ & $\begin{array}{c}\varphi 2 @ 10 \\
0\end{array}$ \\
\hline EC-4 & $4 \varphi 6$ & $4 \varphi 6$ & $\varphi 2 @ 100$ & $4 \varphi 4$ & $4 \varphi 4$ & $\begin{array}{c}\varphi 2 @ 10 \\
0\end{array}$ \\
\hline EC-5 & $4 \varphi 6$ & $4 \varphi 6$ & $\varphi 2 @ 100$ & $4 \varphi 4$ & $4 \varphi 4$ & $\begin{array}{c}\varphi 2 @ 10 \\
0\end{array}$ \\
\hline
\end{tabular}

\section{Wall material characteristics}

\section{Block characteristics}

There are 3 kinds of internal filling block, the specific performance is shown in table 3 .

Tab.3 Block properties

\begin{tabular}{ccc}
\hline type & $\begin{array}{c}\text { volume-weight } /(\mathrm{kN} \text { strength } / \mathrm{M} \\
\left./ \mathrm{m}^{3}\right)\end{array}$ & $\begin{array}{c}\mathrm{Pa} \\
\text { Filling block }\end{array}$ \\
\hline $\begin{array}{c}\text { LEP-J filling blo } \\
\text { ck }\end{array}$ & 7.3 & 2.50 \\
EPS filling block & 7.0 & 2.50 \\
\hline
\end{tabular}

\section{Concrete characteristic}

The frame concrete label is $\mathrm{C} 30$, and the rib concrete label is $\mathrm{C} 20$. The specific performance is shown in table 4. 
Tab.4 Concrete properties

\begin{tabular}{cccc}
\hline $\begin{array}{c}\text { grad } \\
\mathrm{e}\end{array}$ & $\begin{array}{c}\text { volume-weight / } \\
\left(\mathrm{kN} / \mathrm{m}^{3}\right)\end{array}$ & $\begin{array}{c}\text { strength / } \\
\mathrm{MPa}\end{array}$ & $\begin{array}{c}\text { elasticity modulus /x } \\
10^{6} \mathrm{MPa}\end{array}$ \\
\hline $\mathrm{C} 20$ & 24.0 & 21.4 & 0.0262 \\
$\mathrm{C} 30$ & 24.0 & 33.2 & 0.0287 \\
\hline
\end{tabular}

\section{Steel features}

Frame C steel, rib L steel and wall rebar are shown in table 5.

Tab.5 Steel properties

\begin{tabular}{|c|c|c|c|c|c|}
\hline $\begin{array}{l}\text { specificat } \\
\text { ion }\end{array}$ & grade & $\begin{array}{l}\text { yield stress/ } \\
\mathrm{MPa}\end{array}$ & $\begin{array}{c}\text { ultimate stress } \\
\text { /MPa }\end{array}$ & $\begin{array}{c}\text { elasticity modulus / } \\
\times 10^{6} \mathrm{MPa}\end{array}$ & $\begin{array}{c}\text { elongation } \\
1 \%\end{array}$ \\
\hline$\varphi 2$ & $\begin{array}{l}\text { HPB2 } \\
35\end{array}$ & 240 & 269 & 0.21 & 2.20 \\
\hline$\varphi 4$ & $\begin{array}{l}\text { HPB2 } \\
35\end{array}$ & 627 & 761 & 0.22 & 0.76 \\
\hline$\varphi 6$ & $\begin{array}{l}\mathrm{HPB} 2 \\
35\end{array}$ & 566 & 666 & 0.21 & 4.60 \\
\hline C5 & Q235 & 381 & 508 & 0.25 & - \\
\hline $\begin{array}{c}\mathrm{L} 30 \times 30 \times \\
3\end{array}$ & Q235 & 306 & 428 & 0.19 & 0.42 \\
\hline
\end{tabular}

\section{Test loading plan}

The test use simulated earthquake load. Vertical load was $110 \mathrm{kN}$ (simulated the load on the bottom wall of the seven-storey residential building), and the load was in place at one time, and the whole experiment process was kept unchanged. The horizontal load is low cyclic loading, and after the vertical load is stable, it is loaded step by step. Due to poor constraints of LEP-J block and low ultimate stress of EPS block, expected EC-4 and EC-5 walls limit displacement is small, so the EC-1, EC-2, and EC-3 walls load use the force control, EC-4, EC-5 wall load use displacement control. The wall loading method of EC-1, EC-2 and EC-3 is that: in elastic stage, hierarchical loading, $5 \mathrm{kN}$ per level, and 1 reciprocating cycle, in the elastic-plastic stage, the loading is graded, $5 \mathrm{~mm}$ is loaded at each stage, and the reciprocating cycle is 3 times, after the wall horizontal load is reduced by $15 \%$, the cyclic loading is not repeated. The wall loading method of EC-4 and EC-5 is that: in elastic stage, $0.5 \mathrm{~mm}$ loading at each stage, and 1 reciprocating cycle, after entering the elastic-plastic stage, each stage is loaded with $4 \mathrm{~mm}$ and the reciprocating cycle is 3 times.

\section{Test results}

Under the given load, the EC-1 EC-5 wall all starts from the elastic phase and gradually enters the elastic-plastic stage and eventually damages. However, different wall frame, rib and inner fill block material are different. The bearing performance of each wall in each stage is different, and the final destruction of 5 walls is shown in figure 2. 


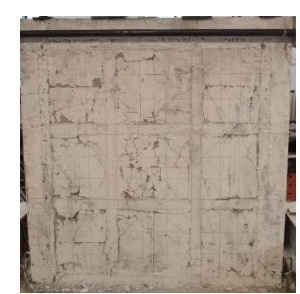

( a ) EC-1

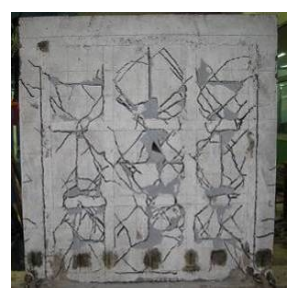

( b ) EC-2

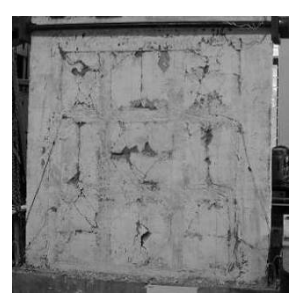

(c) EC-3

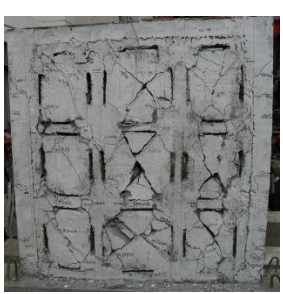

( d ) EC-4

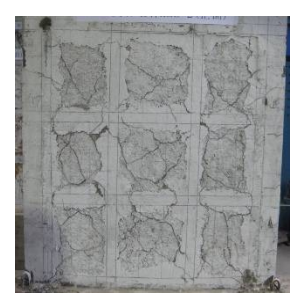

(e ) EC-5

Fig. 2 Failure pictures for walls

The following conclusions can be drawn by analyzing the ultimate failure characteristics of the walls.

1) During the low-cycle loading under the simulated earthquake, the wall has experienced three stages: elasticity, elastic-plastic and destruction. The overall deformation of the wall is smaller in the initial elastic stage of loading. During the elastic-plastic stage, the deformation of the wall increases, and the cracks begin to appear in the wall filled with cracks, and some cracks extend to the ribs. When loading increases to ultimate load, the walls appear a large number of inclined cracks, and rib fracture through rib beam, column, and extends to the outer frame beams. Then the wall displacement continue to increase, part of the block began to fall off, then the wall damage.

2) Different wall frame and rib have different constraints, resulting in different seismic performance of the wall. The EC-1 wall is a traditional composite wall, which is the basis of other wall comparisons. The boundary column of EC-2 wall adopts C- shaped steel and concrete, and the wall crack distribution is more uniform and slower. EC-3 wall rib use L type light steel, wall bearing capacity is weaker than EC-2 wall, but superior to EC-1, EC-4 and EC-5. The EC-4 wall adopts LEP-J inner block, the crack develops rapidly during the loading process, and the overall anti-seismic energy of the wall is poor. The EC-5 wall adopts EPS as inner block, and the crack develops slowly at the initial stage of loading, after the crack appearing, the bearing capacity of the wall decreases rapidly.

\section{Conclusions}

In this paper, the following conclusions are drawn from the aseismic performance test of the five extended composite walls.

1) The wall under low cyclic loading which simulated earthquake, have experienced three phases: elastic, elastic-plastic and damage, wall damage type is shear failure, and that is the ideal form of destruction. When the initial elastic stage is loaded, the overall deformation is small, and the wall can be regarded as a whole force component, and the block is coordinated with the ribs and the frame, each of which plays its own performance. During the elastic-plastic stage, the deformation of the wall increases, and the cracks begin to appear in the blocks and some cracks extend to the ribs. When the load continues to increase to the ultimate load, a large number of oblique cracks appear in the wall, and the crack penetrates the ribbed beams and columns, and extends outwards to the outer frame column. Continue to increase the wall displacement, part of the block begins to fall off, and then the wall damage.

2) Different wall frames and ribs lead to different seismic performance of walls. The boundary of EC-1 wall and the rib are all used in traditional rebar, which is the basis of other wall comparison. The frame of EC-2 wall is made of $\mathrm{C}$ steel, which has a great effect on the frame and block, and the crack development of block is slow. The structure of EC-3 is slightly weaker than EC-2 wall with L light steel, but the overall seismic performance is better than EC-1, EC-4 and EC-5. The structure of EC-4 wall is use LEP-J blocks, which is less constrained than the frame and the rib. During the loading process, it cannot effectively suppress the development of the crack, and the overall seismic performance is poor. The EC-5 wall adopts EPS blocks, which shows good energy dissipation characteristics at the beginning of loading, and the crack develops slowly. When the crack appearing, the bearing capacity of the wall decreases rapidly. 
3) The use of L steel in rib and C steel in frame can greatly increase the constraint of block, effectively limit the development of cracks, and greatly improve the seismic performance of the wall. It can obviously improve the ductility of the wall without reducing the ultimate bearing capacity.

\section{Acknowledgements}

This work was financially supported by National Natural Science Foundation of China (51508021 , 51578446).

\section{References}

[1] CHEN Jinshi, GUO Zhengxing. Seismic performance study on space model of the new precast concrete shear wall structure [J]. Construction Technology, 2012, 41(364): 87-89.(in Chinese)

[2] ZHANG Weijing, QIAN Jiaru, MENG Tao, et al. Axial compressive test and analysis of prefabricated hollow shear walls[J]. Architecture Technology, 2009, 40(11): 1040-1042.(in Chinese).

[3] YAO Qianfeng, HUANG Wei, TIAN Jie, et al. Experimental analysis of mechanical characteristics and seismic performance of multi-ribbed panel wall[J]. Journal of building structure, 2004, 25(6): 67-74.(in Chinese).

[4] HUANG Wei, ZHANG Huihui, YAO Qianfeng, et al. Failure modes of ecological composite wall with different filled materi-als[J]. Journal of southeast university, 2009, 39(sup $\square$ ):227-230. (in Chinese). 